\title{
Aspectos da biologia de nidificação de Euplusia mussitans (Fabricius) (Hymenoptera, Apidae, Euglossini)
}

\author{
Blandina Felipe Viana ${ }^{1}$ \\ Edinaldo Luz das Neves ${ }^{2}$ \\ Fabiana Oliveira da Silva ${ }^{2}$
}

\begin{abstract}
Aspects of nesting biology of Euplusia mussitans Fabricius (Hymenoptera, Apidae, Euglossini). The architecture and biology of Euplusia mussitans (Fabricius, 1787) nests were investigated, using trap nests made by wood, which were randomly distributed in a fragment of a coastal sand dunes, in Salvador, Bahia, Brazil $\left(12^{\circ} 56^{\prime} \mathrm{S}\right.$ and $\left.38^{\circ} 21^{\prime} \mathrm{W}\right) .10$ nests were found in cavities with $1.5 \mathrm{~cm}$ in diameter. From them emerged 10 females and 16 males (Sex ratio $=0,38$ ). The nest cells were made of small pieces of bark cemented together with resin. The number of cells in the nests varied from 2 to 4 , with females cells at the inner end and males cells towards the entrance. No significant difference was observed $(t=0.7274, \mathrm{P}>0.05)$ between the medium size for males $(6.3 \mathrm{~mm} \pm 0.16)$ and for females $(6.4 \mathrm{~mm} \pm 0.29)$. The development time of females was longer than males.

KEY WORDS. Euglossini, Euplusia mussitans, bees, nests, trap nests, biology
\end{abstract}

De um modo geral, conhece-se pouco acerca da biologia dos Euglossini, havendo informações quanto a arquitetura de ninhos, para um número reduzido de espécies (SAKAGAMI \& STURM 1965; SAKAGAMI \& MiCHENER 1965; ZuCCHI et al. 1969; MYers \& LOVEleSS 1976; KimSEY 1982; GARÓFAlO et al. 1993; PERUQUETTI \& CAMPOS 1997). Isso deve-se, principalmente, à dificuldade em localizar ninhos naturais desse grupo no campo.

Em um estudo realizado nas dunas litorâneas de Abaeté, Salvador, Bahia, sobre a comunidade de Apoidea, foram utilizados diferentes métodos de monitoramento, dentre os quais iscas odores e ninhos-armadilha.

Durante um período de 12 meses, a cada 10 dias, em que foram utilizadas as iscas odores, Euplusia mussitans (Fabricius, 1787) não foi coletada. Entretanto, utilizando-se a técnica de ninhos-armadilha, amplamente empregada por vários autores (KROMBEIN 1967; CAMILlo et al. 1995; FranKIE et al. 1998; MoRATO \& CAMPOS 2000), no levantamento da fauna de vespas e de abelhas solitárias que nidificam em cavidades pré-existentes, foram obtidos 19 ninhos dessa espécie (VIANA et al. 2001). Tendo sido essa, a segunda espécie mais abundante durante o período amostral. Desses ninhos obtidos, 10 foram levados para estudo em laboratório.

1) Departamento de Zoologia, Instituto de Biologia, Universidade Federal da Bahia. 40170-110 Salvador, Bahia, Brasil. E-mail: blande@.ufba.br

2) Programa de Pós-graduação em Ciências Biológicas, Universidade Federal da Bahia. 40170-110 Salvador, Bahia, Brasil. Bolsista da CAPES. 
As abelhas do gênero Euplusia Moure, 1943 (Eufriesea, segundo KIMSEY 1982) apresentam a mais ampla distribuição geográfica dentre os Euglossini, sendo encontradas desde o México até as montanhas de Córdoba, na Argentina (MOURE 1967). São altamente sazonais, estando os adultos ativos apenas durante dois ou três meses ao ano, principalmente na estação chuvosa (DRESSLER 1982; KIMSEY 1982, 1987; ROUBIK \& ACKERMAN 1987; NEVES \& VIANA 1999).

Este gênero é composto por abelhas solitárias, embora seus ninhos possam se apresentar em agregações. As células de cria são construídas com resina e pedaços de casca de madeira, em superfícies elevadas, em fendas de rochas, buracos em árvores ou no solo, sendo estas características distintivas do gênero (SAKAGAMI \& MiCHENER 1965; ZUCCHI et al. 1969; MICHENER 1974; DRESSLER 1982; KIMSEY 1982, 1987; GARÓFALO et al. 1993).

Registros sobre aspectos da arquitetura de ninhos de E. mussitans, em ninhos encontrados em cavidade abandonada por Xylocopa fimbriata (Fabricius, 1804) em Trinidad, foram citados por KIMSEY (1982).

Estudos sobre biologia e arquitetura de ninhos de espécies que nidificam em cavidades pré-existentes fornecem valiosas informações que ajudam a esclarecer as relações filogenéticas entre os diversos grupos de abelhas (MICHENER 1974). O presente trabalho tem por objetivo ampliar o conhecimento existente sobre abelhas do gênero Euplusia, estudando a arquitetura e biologia de ninhos de E. mussitans, fundados em ninhos- armadilha, nas dunas costeiras da APA de Abaeté.

\section{MATERIAL E MÉTODOS}

Os ninhos de E. mussitans foram fundados em ninhos-armadilha distribuídos ao acaso, em árvores ou arbustos, a aproximadamente 1,5 metros de altura, em uma área de dunas costeiras com vegetação de réstinga na Área de Proteção Ambiental das Lagoas e Dunas de Abaeté (1256'S e 38²1'W), Salvador, Bahia.

Utilizou-se ninhos-armadilha com cavidades de 8, 10, 15 e $20 \mathrm{~mm}$ de diâmetro e $100 \mathrm{~mm}$ de profundidade. Estes eram constituídos de duas peças de

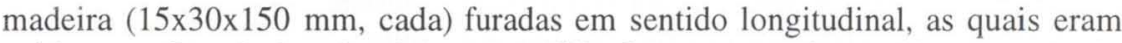
unidas com fita adesiva. Os ninhos-armadilha foram agrupados em blocos contendo 16 peças, sendo quatro de cada classe de diâmetro, com os orifícios de entrada voltados para o mesmo lado.

Os ninhos-armadilha foram inspecionados quinzenalmente no período de maio de 1997 a abril de 1999. As peças contendo ninhos fundados concluídos foram levadas ao laboratório e mantidas dentro de caixas de vidro $(15 \times 15 \times 12 \mathrm{~cm})$, cobertas com tela, até a emergência dos adultos. Estes foram montados, identificados e depositados na coleção de referência do Laboratório de Biologia e Ecologia de Abelhas (LABEA), Instituto de Biologia, Universidade Federal da Bahia. A larva e adultos mortos encontram-se conservados em álcool a 70\% e depositados na mesma coleção.

Os ninhos-armadilha foram abertos, descritos e fotografados. Foram feitas observações quanto ao número de células, presença ou não de células vestibulares, características das partições, tipo de material utilizado para a construção dos ninhos. 
O tamanho dos adultos foi estimado a partir das medidas da largura máxima da cabeça. O comprimento e largura da célula foram medidos com um paquímetro, sendo o volume calculado com a fórmula $\pi \cdot r^{2} \cdot h$. A razão sexual foi determinada dividindo-se o número de fêmeas pelo total de adultos nos ninhos examinados. A existência de diferenças significativas em relação ao comprimento e volume das células, de acordo com o sexo do adulto, foi obtida pelo teste t-student. A relação entre o número de machos e fêmeas produzidos, em função da posição da célula no ninho, foi avaliada pelo teste $X^{2}$ (tabela de contingência).

\section{RESULTADOS}

A arquitetura dos ninhos de E. mussitans foi analisada em 10 ninhos fundados no período de agosto de 1998 a maio de 1999, em ninhos-armadilha de $15 \mathrm{~mm}$ de diâmetro. As medidas das principais estruturas dos ninhos estudados são apresentadas na tabela I.

Tabela I. Medidas das principais estruturas dos ninhos de E. mussitans coletados em ninhos-armadilha na Área de Proteção Ambiental das Lagoas e Dunas de Abaeté, Salvador, Bahia, no período de agosto de 1998 a maio de 1999.

\begin{tabular}{|c|c|c|c|c|c|c|c|c|}
\hline \multirow{3}{*}{$\begin{array}{l}\text { Número } \\
\text { do } \\
\text { ninho }\end{array}$} & \multirow{3}{*}{$\begin{array}{c}\text { Diâmetro } \\
\text { da } \\
\text { entrada }(\mathrm{cm})\end{array}$} & \multirow{3}{*}{$\begin{array}{l}\text { Número } \\
\text { de } \\
\text { células }\end{array}$} & \multicolumn{6}{|c|}{ Medidas das células } \\
\hline & & & \multicolumn{2}{|c|}{ Comprimento $(\mathrm{cm})$} & \multicolumn{2}{|c|}{ Largura $(\mathrm{cm})$} & \multicolumn{2}{|c|}{ Volume $\left(\mathrm{cm}^{3}\right)$} \\
\hline & & & Variação & $X \pm E P$ & Variação & $X \pm E P$ & Variação & $X \pm E P$ \\
\hline 1 & 1,5 & 3 & $1,6-2,0$ & $1,8 \pm 0,21$ & $1,6-1,7$ & $1,7 \pm 0,06$ & $3,22-4,52$ & $3,9 \pm 0,65$ \\
\hline ॥ & 1,5 & 3 & $1,5-2,0$ & $1,7 \pm 0,26$ & $1,2-1,3$ & $1,3 \pm 0,06$ & $1,99-2,26$ & $2,1 \pm 0,14$ \\
\hline III & 1,5 & 3 & $1,5-1,6$ & $1,5 \pm 0,06$ & 1,3 & $1,3 \pm 0,01$ & $1,99-2,12$ & $2,0 \pm 0,08$ \\
\hline IV & 1,5 & 4 & $1,8-2,0$ & $1,9 \pm 0,10$ & $1,1-1,2$ & $1,2 \pm 0,05$ & $1,90-2,15$ & $2,0 \pm 0,10$ \\
\hline V & 1,5 & 2 & $1,8-2,0$ & $1,9 \pm 0,14$ & 1,2 & $1,2 \pm 0,01$ & $2,03-2,26$ & $2,1 \pm 0,16$ \\
\hline VI & 1,5 & 4 & 1,5 & $1,5 \pm 0,01$ & $1,3-1,4$ & $1,3 \pm 0,06$ & $1,99-2,31$ & $2,1 \pm 0,18$ \\
\hline VII & 1,5 & 4 & $1,5-1,7$ & $1,6 \pm 0,10$ & $1,7-1,8$ & $1,7 \pm 0,05$ & $3,40-4,32$ & $3,7 \pm 0,44$ \\
\hline VIII & 1,5 & 3 & $1,5-1,7$ & $1,6 \pm 0,12$ & 1,6 & $1,6 \pm 0,01$ & $3,01-3,42$ & $3,1 \pm 0,23$ \\
\hline IX & 1,5 & 3 & $1,5-1,8$ & $1,6 \pm 0,15$ & $1,2-1,3$ & $1,2 \pm 0,06$ & $1,70-2,12$ & $1,9 \pm 0,23$ \\
\hline$x$ & 1.5 & 2 & $1,5-2,2$ & $1,8 \pm 0,49$ & 1,2 & $1,2 \pm 0,01$ & $1,70-2,49$ & $2,1 \pm 0,56$ \\
\hline
\end{tabular}

O comprimento total dos ninhos estudados varia de 5,3 a $8,0 \mathrm{~cm}(X=6,7 \pm$ 1,10 ), com duas a quatro células dispostas em série linear, construídas com resina e pedaços de madeira, formando um aglomerado resistente.

Internamente as células apresentam-se com formato oval, revestidas com resina, o que lhes confere um aspecto liso e brilhante. As divisórias das células possuem espessura entre 0,16 e $0,60 \mathrm{~cm}(X=0,3 \pm 0,15)$, e posição oblíqua em relação ao plano horizontal. A espessura da parede lateral dos ninhos varia de 0,12 a $0,30 \mathrm{~cm}(X=0,2 \pm 0,05)$. As cavidades dos ninhos-armadilha não foram ocupadas em sua totalidade restando, geralmente, um espaço vazio entre a última célula construída e a entrada dos ninhos-armadilha que varia de 1,0 a $4,7 \mathrm{~cm}$ de comprimento ( $\mathrm{X}=3,4 \pm 1,05$ ). Células vestibulares estavam presentes em três ninhos, em posições variadas (Tab. II).

A partir dos ninhos analisados emergiram 10 fêmeas e 16 machos, resultando em razão sexual de 0,38 . Houve produção de fêmeas apenas nas primeira e segunda 
células, enquanto os machos emergiram a partir de todas as células (Tab. II), sendo que a maioria deles foram produzidos nas últimas células construídas $\left(X^{2}=7,815\right.$; $\mathrm{p}<0,05)$.

Tabela II. Data de fundação, localização dos indivíduos nas células e razão sexual obtidos dos ninhos de E. mussitans coletados em ninhos-armadilha na Área de Proteção Ambiental das Lagoas e Dunas de Abaeté, Salvador, Bahia. ( $\sigma^{\star}$ M) Macho adulto morto.

\begin{tabular}{|c|c|c|c|c|c|c|c|c|}
\hline \multirow{2}{*}{$\begin{array}{l}\text { Número do } \\
\text { ninho }\end{array}$} & \multirow{2}{*}{$\begin{array}{c}\text { Data de fundação } \\
\text { do ninho }\end{array}$} & \multicolumn{4}{|c|}{ Localização dos individuos nas células } & \multicolumn{2}{|c|}{ Razão sexual } & \multirow{2}{*}{$\begin{array}{l}\text { Total de } \\
\text { adultos }\end{array}$} \\
\hline & & $1^{3}$ céluia & $2^{\mathrm{a}}$ célula & $3^{\mathrm{a}}$ célula & $4^{a}$ célula & Macho & Fêmea & \\
\hline 1 & 20/08/1998 & q & $\sigma^{n}$ & $\sigma^{*}$ & - & 2 & 1 & 3 \\
\hline ॥ & 03/09/1998 & Vazia & q & $\sigma^{*}$ & Vazia & 1 & 1 & 2 \\
\hline III & 03/09/1998 & \& & $\sigma$ & $\sigma^{*}$ & $\sigma^{*}$ & 3 & 1 & 4 \\
\hline IV & 03/09/1998 & q & q & $\sigma^{*}$ & - & 1 & 2 & 3 \\
\hline v & 03/09/1998 & q & $q$ & $\sigma^{2}$ & - & 1 & 2 & 3 \\
\hline$v_{1}$ & 03/09/1998 & $\sigma^{\prime} M$ & ? & - & - & 1 & 1 & 2 \\
\hline VII & 24/09/1998 & $\sigma^{*} M$ & q & $\sigma^{\prime \prime}$ & $\sigma^{\pi}$ & 3 & 1 & 4 \\
\hline VIII & $22 / 10 / 1998$ & Vazia & $a^{\circ}$ & $\sigma^{\circ}$ & - & 2 & 0 & 2 \\
\hline IX & 10/02/1999 & $q$ & $\sigma^{\circ} \mathrm{M}$ & - & - & 1 & 1 & 2 \\
\hline$x$ & 27/05/1999 & Larva morta & Vazia & $\sigma$ & Vazia & 1 & 0 & 1 \\
\hline
\end{tabular}

Não houve diferença estatisticamente significativa ( $t=0,7274, p>0,05)$ entre o tamanho (largura da cabeça) dos machos $(6,3 \mathrm{~mm} \pm 0,16)$ e das fêmeas $(6,4 \mathrm{~mm} \pm$ $0,29)$, assim como o volume médio das células ( macho $=2,7 \mathrm{~cm}^{3} \pm 0,69$; fêmeas $=2,6$ $\left.\mathrm{cm}^{3} \pm 0,98\right)$ não variou em função do sexo do adulto $(\mathrm{t}=0,3198 \mathrm{p}>0,05)$.

Entretanto, o comprimento médio das células das fêmeas $(1,8 \mathrm{~cm} \pm 0,26)$ é significativamente maior $(\mathrm{t}=2,566, \mathrm{p}<0,05)$ do que o das células dos machos $(1,6 \mathrm{~cm} \pm 0,11)$.

Na tabela III são apresentados os intervalos de tempo entre as fundações dos ninhos (mais especificamente a época em que os ninhos foram detectados no campo e removidos para o laboratório) e a emergência dos adultos (machos e fêmeas), em ordem crescente de nascimentos (em dias).

Tabela III. Intervalos de tempo (em dias) entre as fundações dos ninhos de E. mussitans e a emergência dos adultos (machos e fêmeas), em ordem crescente de nascimentos, na Área de Proteção Ambiental das Lagoas e Dunas de Abaeté, Salvador, Bahia. (o M) Macho adulto morto.

\begin{tabular}{|c|c|c|c|c|c|}
\hline \multirow{2}{*}{ Ninho } & \multirow{2}{*}{ Data de coleta } & \multicolumn{4}{|c|}{ Tempo de desenvolvimento dos adultos, por ordem de nascimento } \\
\hline & & 1 & 2 & 3 & 4 \\
\hline 1 & $20 / 08 / 1998$ & $269 \sigma^{\circ}$ & $278 \sigma^{\circ}$ & 318 우 & - \\
\hline II & 03/09/1998 & $2870^{x}$ & 318 ㅇ & - & - \\
\hline III & 03/09/1998 & $2710{ }^{*}$ & $2810^{*}$ & $291 \sigma^{*}$ & 318 ㅇ \\
\hline IV & $03 / 09 / 1998$ & 2910 & 3419 & 345 웅 & - \\
\hline V & 03/09/1998 & 2910 & $309 q$ & 310 우 & - \\
\hline VI & 03/09/1998 & $307 \%$ & $\sigma^{*} \mathrm{M}$ & - & - \\
\hline VII & $24 / 09 / 1998$ & $275 \sigma^{\circ}$ & $2750^{\circ}$ & 317 우 & $\sigma^{n} \mathrm{M}$ \\
\hline VIII & $22 / 10 / 1998$ & $276 \sigma^{x}$ & 278 o & - & - \\
\hline $\mathrm{IX}$ & $10 / 02 / 1999$ & 145 우 & $\sigma^{*} \mathrm{M}$ & - & - \\
\hline$x$ & $27 / 05 / 1999$ & $190^{\circ}$ & - & - & - \\
\hline
\end{tabular}


O período de desenvolvimento, em geral, foi longo. O tempo médio de desenvolvimento dos machos foi de 260,15 ( $\mathrm{dp}=72,8)$ dias e o das fêmeas de 302,8 $(\mathrm{dp}=56,9)$ dias. Para os ninhos fundados em agosto, setembro e outubro de 1998 as emergências ocorreram entre maio a agosto de 1999 (período total de 11 meses). Para os ninhos fundados em fevereiro, o intervalo entre a fundação e a emergência foi mais curto, de quatro a cinco meses. O intervalo entre os nascimentos dos machos em um mesmo ninho variou entre 03 a 10 dias e entre machos e fêmeas de 24 até 50 dias.

\section{DISCUSSÃo}

Os ninhos de E. mussitans descritos neste estudo, apresentam características semelhantes àquelas observadas em ninho natural dessa espécie, construído em cavidade abandonada por X. fimbriata (KIMSEY 1982), bem como àqueles construídos por E. surinamensis (Linnaeus, 1758), exceto pelo fato desta última não nidificar em cavidades tubulares (KIMSEY 1982; MYERS \& LOVELESS 1976).

De acordo com SAKAGAMI \& MichenER (1965), a utilização de grande quantidade de pedaços de madeira e resina para a construção das células, torna a arquitetura dos ninhos das abelhas desse gênero distintiva dentre os Euglossinae. Aspectos da arquitetura do ninho como, o tipo de material utilizado, o fechamento do ninho e, principalmente, a presença de células vestibulares (vazias) podem estar associados à proteção contra ataques de inimigos naturais.

Em geral, os ninhos construídos em cavidades pré-existentes, caracterizamse por uma série de células individualizadas formadas por divisórias. Embora a arquitetura desses ninhos e a disposição de suas células dependam do espaço disponível na cavidade, o número de células por ninho pode apresentar uma grande variabilidade inter-específica e intra-específica (Raquel Pérez-Maluf comunicação pessoal).

Neste estudo, observou-se um número menor de células por ninho de $E$. mussitans, comparado ao encontrado em ninhos naturais desta espécie ( 6 células) e ao de outras espécies do gênero como: E. surinamensis (3-6 células), E. laniventris (Ducke, 1902) (9 células) e E. lucifera (Kimsey, 1977) (8-9 células) (KIMSEY 1982). De um modo geral, os ninhos-armadilha apresentavam espaço disponível suficiente para a construção de mais uma ou duas células, indicando que a produção de células não deve ter sido limitada pelo comprimento total da cavidade dos ninhos-armadilha.

Embora tenha sido oferecido no campo diferentes classes de diâmetro $(0,8$ a 2,0 cm) de ninhos-armadilha em quantidades eqüitativas, o diâmetro interno das cavidades utilizadas por E. mussitans em Abaeté foram exclusivamente de 1,5 cm. Esse diâmetro assemelha-se ao encontrado em ninho natural dessa espécie (1,5-1,7 $\mathrm{cm}$ ), em Trinidad (KIMSEY 1982). Variação semelhante foi observada para as espécies E. surinamensis, E. auriceps (Mocsary, 1898) e E. violacea (Blanchard, 1840) (KimSEY 1982; GARófalo et al. 1993; PERUQueTti \& CAMPOS 1997). Isso deve ocorrer como consequêencia da pequena variação no tamanho corporal dos representantes dessas espécies. GARÓFALO et al. (1993) observaram ainda que, em cavidades com diâmetros superiores a $20 \mathrm{~mm}, E$. violacea tende a construir ninhos aglomerados. 
A razão sexual obtida, assemelha-se àquela encontrada para outras espécies do gênero. GARÓFALO \& SERRANO (1992) e PERUQUETTI \& CAMPOS (1997) encontraram uma razão sexual de 0,38 e 0,31 , respectivamente, para E. violacea, enquanto GARÓFALO et al. (1993) encontraram 0,39 para E. auriceps. Em Abaeté, o fato de terem emergido mais machos que fêmeas nos ninhos de E. mussitans, deve estar associado à abundância dos recursos disponíveis no ambiente. Como as fêmeas, sexo mais custoso, requerem maior quantidade de alimento para se desenvolver, a sua produção estaria condicionada às épocas em que os recursos fossem mais abundantes (SIHAG 1983; FROHLICH \& TEPEDINO 1986; BROCKMANN \& GRAFEN 1992).

O maior comprimento apresentado pelas células das fêmeas também deve estar relacionado à maior quantidade de alimento aprovisionado, requerido para o desenvolvimento das mesmas.

A maior produção de fêmeas nas primeiras células construídas, como observado nos ninhos de E. mussitans estudados, é uma característica comum para muitas espécies de abelhas e vespas que nidificam em cavidades pré-existentes (KROMBEIN 1967), tendo sido também observada em outras espécies do gênero (ZUCCHI et al. 1969; Garófalo \& Serrano 1992; Garófalo et al. 1993; PeruQuetTi \& CAMPOS 1997).

Entretanto, pode ocorrer a produção de machos a partir das primeiras células, embora a probabilidade de o macho emergir vivo seja muito pequena. Isso pode explicar a morte dos machos que emergiram nas primeiras células dos ninhos VI e VII (Tab. II). Neste caso, os machos ao completarem o seu desenvolvimento, ficaram impedidos de sair do ninho devido à célula seguinte (de onde nasceria uma fêmea) permanecer fechada, já que as fêmeas desenvolvem-se mais lentamente.

Apesar das fêmeas terem emergido apenas nas duas primeiras células, não podemos afirmar que a larva morta do ninho X é de uma fêmea pois, como observado nos ninhos VI e VII (Tab. II), pode ocorrer a produção de machos em células anteriores às das fêmeas.

Quanto ao período de desenvolvimento das crias, os resultados obtidos para E. mussitans sugerem que essa espécie segue o padrão da maioria das espécies já estudadas, do gênero (ZuCCHI et al. 1969; GARÓFAlO et al. 1993; PERUQUETTI \& CAMPOS 1997). Esse longo período de desenvolvimento deve-se à capacidade das espécies desse gênero, de permanecerem por vários meses em diapausa pré-pupal, permitindo a ocorrência de apenas uma geração por ano.

AGRADECIMENTOS. À Capes e ao CADCT/SEPLANTEC pelo auxílio financeiro; a Ciáxares Magalhães Carvalho e Alex Fabian Rabelo Teixeira pelo auxílio na instalação e inspeção dos ninhos no campo; ao Pe. Jesus Santiago Moure, pela confirmação da identificação da espécie de abelha.

\section{REFERÊNCIAS BIBLIOGRÁFICAS}

Brockmann, H.J. \& A. Grafen. 1992. Sex ratios and life-history of a solitary wasp, Trypoxylon (Trypargilum) politum (Hymynoptera: Sphecidae). Behav. Ecol. Sociobiol. 30: 7-27.

Camillo, E; C.A. Garófalo; J.C. Serrano \& G. Mucillo. 1995. Diversidade e Abundância Sazonal de Abelhas e Vespas Solitárias em ninhos armadilhas (Hymenoptera, Apocrita, Aculeata). Revta bras. Ent. 39: (2): 459-470.

Revta bras. Zool. 18 (4): 1081 - 1087, 2001 
DREssler, R.L. 1982. Biology of the orchid bees (Euglossini). Ann. Rev. Ecol. Syst. 13: 373-394.

Frankie, G.W.; R.W. Thorp; L.E. Newstrom-Lloyd; M.A. Rizzardi; J.F. Barthel; T.L. Griswold; J. KIM \& S. KAPPAGODA. 1998. Monitoring solitary bees in modified wildland habitats: Implications for bee ecology and conservation. Environ. Entomol. 27 (5): 1137-1148.

Frohlich, D.R. \& V.J. TEPEDINO. 1986. Sex ratio, parental investment and interparent variability in nesting success in a solitary bee. Evolution 40: 142-151.

Garófalo, C.A. \& J.C. Serrano. 1992. Reutilização do ninho por Eufrisea violacea (Hymenoptera: Apidae: Euglossini). Naturalia, São Paulo, (Especial): 234.

Garófalo, C.A.; E. Camillo; J.C. Serrano \& J.M.M. Rebêlo. 1993. Utilization of traps nests by Euglossini species (Hymenoptera:Apidae). Rev. Brasil. Biol. 53 (2): 177-187.

KIMSEY, L.S. 1982. Systematics of bees of the genus Eufriesea (Hymenoptera, Apidae). Univ. California Publ. Entom. 95: 1-125.

1987. Generic relationships within Euglossini (Hymenopter: Apidae). Syst. Entomol. 12: 63-72

Krombein, K.V. 1967. Trap-nesting wasps and bees: Life, histories, nests and associates. Washington, D.C., Smithsonian Press, 570p.

Michener, C.D. 1974. The Social Behavior of the Bees. Cambridge, Harvard Univ. Press, 403p.

Morato, E.F. \& L.A.O. CAmpos. 2000. Efeitos da fragmentação florestal sobre vespas e abelhas solitárias em uma área da Amazônia Central. Revta bras. Zool. 17 (2): 429-444.

MourE, J.S. 1967. A check-list of the known Euglossine bees (Hymenoptera, Apidae). Atas Simpos. Biota Amazôn., Curitiba, 5: 395-415

MYeRS, J.D. \& M.D. LovelESs. 1976. Nesting Aggregations of the Euglossini bee Euplusia surinamensis (Hymenoptera: Apidae): Individual interations and the advantage of living together. Can. Ent. 108 (1): 1-6.

Neves, E.L. \& B.F. Viana. 1999. Comunidade de Machos de Euglossinae (Hymenoptera, Apidae) das Matas Ciliares do Médio Rio São Francisco, Bahia. An. Soc. Entomol. Brasil 28 (2): 201-210.

Peruquetti, R.C. \& L.A.O. Campos. 1997. Aspectos da Biologia de Euplusia violacea (Blanchard) (Hymenoptera, Apidae, Euglossini). Revta bras. Zool. 14 (1):91-97.

RoubIK, D.W. \& J.D. ACKERMAN. 1987. Long-term ecology of euglossine orchid-bees (Apidae: Euglossinae) in Panamá. Oecologia 73: 321-333.

SAKagami, S.F. \& H. Sturm. 1965. Euplusia longipenis (Friese) und ihre merkwürdigen brutzellen aus Kolumbien (Hymenoptera, Apidae). Insecta Matsumurana 28: 83-92.

SAKAGAmi, S.F. \& C.D. Michener. 1965. Notes on the nests of two euglossine bees, Euplusia violacea and Eulaema cingulata (Hymenoptera, Apidae). Ann. Zool. Japon. 38 (4): 216-222.

SiHAG, R.C. 1983. Life cycle pattern, seasonal mortality, problem of parasitization and Sex ratio pattern in alfafa pollinating megachilid bees. Z. ang. Ent. 96: 368-379.

VianA, B.F.; F.O. Silva \& A.M.P. KLEINERT. 2001. Diversidade e sazonalidade de abelhas solitárias (Hymenoptera: Apoidea) em dunas litorâneas no nordeste do Brasil. Neotrop. Ent. 30 (2): 245-251.

ZuCCHI, R.; S.F. SAKagami \& J.M.F. CAMARgo. 1969. Biological observations on a neotropical parasocial bee, Eulaema nigrita, with a review on the biology of Euglossinae (Hymenoptera, Apidae). A comparative Study. Jour. Fac. Sc. Hokkaido Univ., Zoology, 17 (6): 271-379.

Recebido em 14.IX.2000; aceito em 22.X.2001. 